\title{
Structural Behavior of Reinforced Concrete Beams Incorporating Foamed Glass as Aggregates
}

\author{
Dawood S. Atrushi \\ Department of Civil Engineering, College of Engineering, University of Duhok, \\ Duhok, Kurdistan Region - F.R. Iraq
}

\begin{abstract}
Natural resources that are utilized in civil engineering applications can be saved by replacing them with some recycled materials to produce sustainable concrete with required mechanical and durability properties. In recent years, recycled glass is being used as aggregates in concrete production in many countries across the world. In the present study, the structural properties of reinforced concrete beams containing foamed glass (FG) as a partial natural coarse aggregate replacement are investigated. Five concrete mixes were employed to conduct the present study. The coarse aggregate was replaced with $0 \%, 25 \%, 50 \%, 75 \%$, and $100 \%$ (by volume) of FG. Four point-loading flexural tests on beams were conducted up to failure. The results showed that the compressive strength was decreasing linearly with the increasing amount of FG. It was also observed that the ductility of the reinforced concrete beams significantly improved. However, the load-carrying capacity of the beam and load at which the first crack occurs was reduced. It was concluded that the inclusion of FG in structural concrete applications is possible and the structural behavior of concrete beams proved to be similar to that of other types of lightweight aggregate concrete such as wood and plastic aggregates used in similar structural elements.
\end{abstract}

Index Terms-Aggregate, Concrete, Foamed glass, Reinforced concrete beam, Strength, Structural behavior.

\section{INTRODUCTION}

The environmental building design and construction have recently witnessed a surge in the consideration of the sustainability of structure and its effects. Natural materials that are utilized in the construction of a project can be saved by replacing them with recycled lightweight aggregate to produce lightweight aggregate concrete. The commercial demand for light yet strong concrete has been gaining popularity for the past few decades in the construction industry, such as in concrete cellular blocks (Rostam, Ali and Atrushi, 2016). The relatively heavy self-weight of normal concrete where the density is about $2400 \mathrm{~kg} / \mathrm{m}^{3}$, poses risks of earthquake damage in a structure (Kilic, et al.,

ARO-The Scientific Journal of Koya University

Vol. IX, No.1 (2021), Article ID: ARO.10746, 60 pages

DOI:10.14500/aro.10746

Received: 01 November 2020; Accepted: 01 February 2021

Regular research paper: Published: 01 March 2021

Corresponding author's e-mail: dawood.sulaiman@uod.ac Copyright (C) 2021 Dawood S. Atrushi. This is an open-access article distributed under the Creative Commons Attribution License.
2003); in most cases, high rise buildings are affected during earthquakes due to the higher unit weight of normal concrete (Wuest, Denarié and Bruhwiler, 2007). Lighter concrete offers design flexibility and considerable cost savings due to its inherent economies and advantages over normal concrete in a variety of structural applications by providing less dead load, longer spans such as long-span bridges and flyovers, and low heat conductivity (Shafigh, et al., 2011).

Glass is amongst the oldest man-made materials and as such has been used for many years in various applications. As a result, a large volume of post-consumer glass is being generated and discarded often which is likely to increase considerably in the future. Therefore, in recent years several studies have been conducted to evaluate and promote the potential use of waste glass in new concrete production. As a result, waste and recycled glass is now being used as aggregates in concrete production in many countries across the world. Foamed glass (FG) aggregates offer several advantages such as the design of lightweight concrete and its presence as an environmentally-friendly material by preserving the environment through means of reducing landfills and saving more natural resources. However, the use of FG aggregates in concrete production as a partial or full replacement to natural aggregates has generally indicated toward a decrease in the compressive strength in comparison to normal concrete. It was also observed that mixes containing FG aggregates tend to gain slightly higher early compressive strength compared to normal concrete; this could be due to the high alkali content in the FG aggregates (Adom-Asamoah and Afrifa, 2010). In general, with an increase in the replacement of natural aggregates with recycled materials a decrease in compressive strength has been reported (Herki and Khatib, 2016). Investigations on the full replacement of natural aggregates by FG aggregates have shown a substantial drop in the mechanical and durability properties of the concrete which does not even meet the required 28-days strength and durability performance (Shuab and Ray, 1991; Demirbog and Gu, 2003; Rossignolo, Agnesini and Morais, 2003; Hossain, 2004; Babu, Babu and Wee, 2005; Gennaro, et al., 2008; Subasi, 2009; Limbachiya, Meddah and Fotiadou, 2012). The authors express that there are still gaps in our knowledge of the properties and structural behavior of concrete containing $\mathrm{FG}$; because concrete properties can vary considerably depending on 
the type of FG and the technique of recycling used, and so any conclusions may only be valid for the specific project studied. There is not enough information in the literature on the structural behavior of concrete containing FG; therefore, in this study; an experimental program was conducted to investigate the structural behavior of reinforced concrete beams incorporating FG as natural aggregates replacement.

\section{Materials AND Methods}

The cement used was ordinary Portland cement. The fine aggregates used were river sand with particles ranging from $63 \mu \mathrm{m}$ to $4 \mathrm{~mm}$ in size. The coarse aggregates were natural gravel and stones with particles ranging from $4 \mathrm{~mm}$ to $20 \mathrm{~mm}$ in size. The foam glass coarse particles, shown in Fig. 1, used as partial replacement of natural coarse aggregates were also similar in size ranging from $4 \mathrm{~mm}$ to $20 \mathrm{~mm}$, where particle size distribution or grading is done according to BS EN 933$1: 1997$. Foam glass was originally manufactured from waste glass by generating a gas in glass at a temperature between $700^{\circ} \mathrm{C}$ and $900^{\circ} \mathrm{C}$, where foaming agents such as calcium sulfate $\left(\mathrm{CaSO}_{4}\right)$ or calcium carbonate $\left(\mathrm{CaCO}_{3}\right)$ are also added (Hurley, 2003). The gas expands thus producing a structure of cells to form a porous body. The density of coarse aggregate and $\mathrm{FG}$ is $1200 \mathrm{~kg} / \mathrm{m}^{3}$ and $267 \mathrm{~kg} / \mathrm{m}^{3}$, respectively.

For all concrete mixtures, the cement content and the $\mathrm{W} / \mathrm{C}$ ratio were kept constant at $330 \mathrm{~kg} / \mathrm{m}^{3}$ and 0.5 , respectively. The mixtures had proportions of 1 (cement): 2 (fine aggregates): 4 (coarse aggregates). For this experimental program, five mixtures were carried out consisting of three reinforced concrete beams for each mixture with rectangular cross-sections of $100 \mathrm{~mm}$ width $\times 150 \mathrm{~mm}$ depth $\times 700 \mathrm{~mm}$ length. The first mix, which was used as the reference mix, comprises of $100 \%$ natural aggregates. In the remaining mixes the natural aggregates have been partially replaced by different amounts of FG aggregates in terms of volume with replacement levels of $25 \%, 50 \%, 75 \%$, and $100 \%$.

The variation in the number of replacements was used to obtain more data which could be used to draw a better conclusion. Table I illustrates the mix combinations, and the given numbers $0-187.2 \mathrm{~kg}$ for the FG have the same volume of the $1316-0 \mathrm{~kg}$ of coarse aggregate. The grading curves complied with BS EN 933-1:1997 for the natural and FG aggregates and are presented in Fig. 2.

A total of 15 reinforced beams were made from five different mixtures as stated previously. The number of compression bars was two for all beams, but those in tension consisted of three for each concrete beam with $12 \mathrm{~mm}$ bar diameter. The compression reinforcement at the top was primarily for holding purposes and ease of holding stirrups upright. The shear links were $8 \mathrm{~mm}$ diameters and placed at $50 \mathrm{~mm}$ centers to the sides and $75 \mathrm{~mm}$ centers toward flexural zones as shown in Fig. 3b. Loading set-up for the reinforced concrete beams is shown in Fig. 3a. The yield stress of the steel bars is $415 \mathrm{MPa}$.

Three reinforced concrete beams along with three cubes $(100 \mathrm{~mm} \times 100 \mathrm{~mm} \times 100 \mathrm{~mm})$ were cast from each concrete

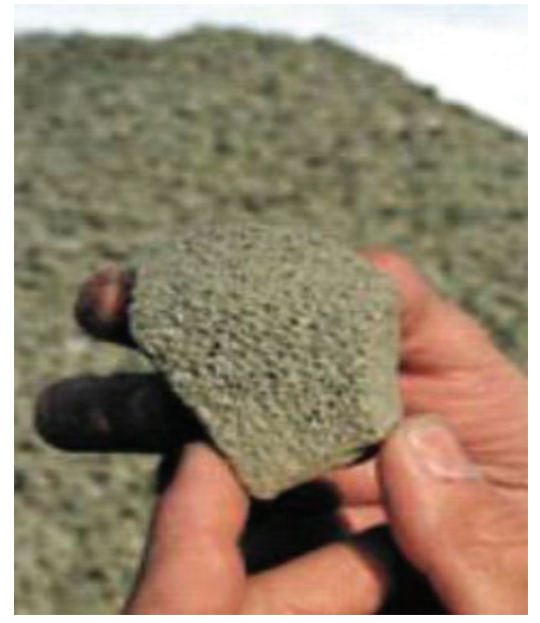

Fig. 1. Foam glass coarse particle.

TABLE I

FULl DetAILS OF CONCRETE MiXTURES (KG/M $\left.{ }^{3}\right)$

\begin{tabular}{lccccccc}
\hline \hline Mix No. & FG (\%) & Cement & Water & FA & CA & FG & W/C \\
\hline 1 & 00 & 330 & 165 & 658 & 1316 & 0 & 0.5 \\
2 & 25 & 330 & 165 & 658 & 987 & 47.1 & 0.5 \\
3 & 50 & 330 & 165 & 658 & 658 & 94.3 & 0.5 \\
4 & 75 & 330 & 165 & 658 & 329 & 140.1 & 0.5 \\
5 & 100 & 330 & 165 & 658 & 0 & 187.2 & 0.5 \\
\hline \hline
\end{tabular}

mix. Plywood mold was used for the beams whereas steel molds conforming to BS EN 12390-2:2012 was used for the cubes. Before casting began, the molds were visually inspected and cleaned thoroughly. Thereafter, a thin layer of oil was applied to the inside surfaces of the molds for easy de-molding.

The concrete mixer was cleaned and slightly damped with water to avoid any absorption of water by the concrete mixer. The required material; fine aggregates, coarse aggregates, FG, and cement were then gently poured into the mixer. Once all the dry materials were inside, the mixer water was then poured little by a little while mixing. After almost 5 min of through mixture until the texture of the concrete was satisfied, the mixing process was stopped and a slump test was carried out in accordance to BS EN 12350-2:2009 to test the properties of fresh concrete such as concrete consistency and the workability.

In the meantime, an already prepared reinforcement cage was gently placed into the molds after applying the thin layer of oil on the inside surface, the appropriate cover was provided for top and bottom along with both sides. Concrete was poured into the molds up to about half level and then compacted using a vibrator table, and the second layer of concrete was then poured to the top level of the molds and compacted again. Along with the beams, three cubes of $100 \mathrm{~mm} \times 100 \mathrm{~mm} \times 100 \mathrm{~mm}$ from each mix combination to determine the mechanical properties were also prepared in a similar manner using a testing machine of $3000 \mathrm{kN}$ capacity at the loading rate of $0.6 \mathrm{MPa} / \mathrm{s}$ complied with BS EN 12390-4:2000. Fresh concrete was poured into the steel molds in three equal layers, and then compacted to a smooth 


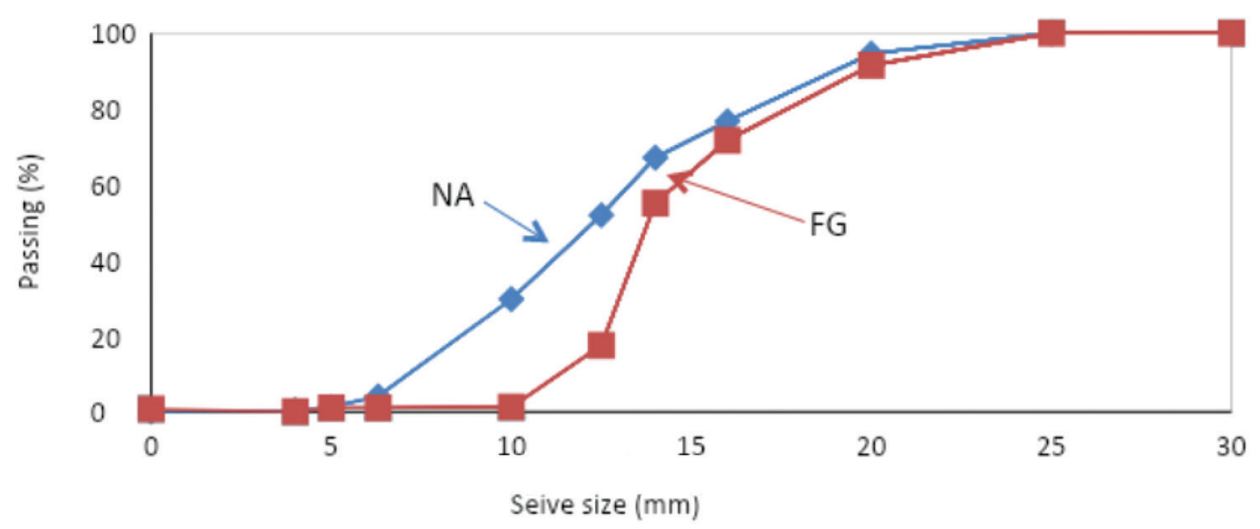

Fig. 2. Particle size distribution of aggregates.

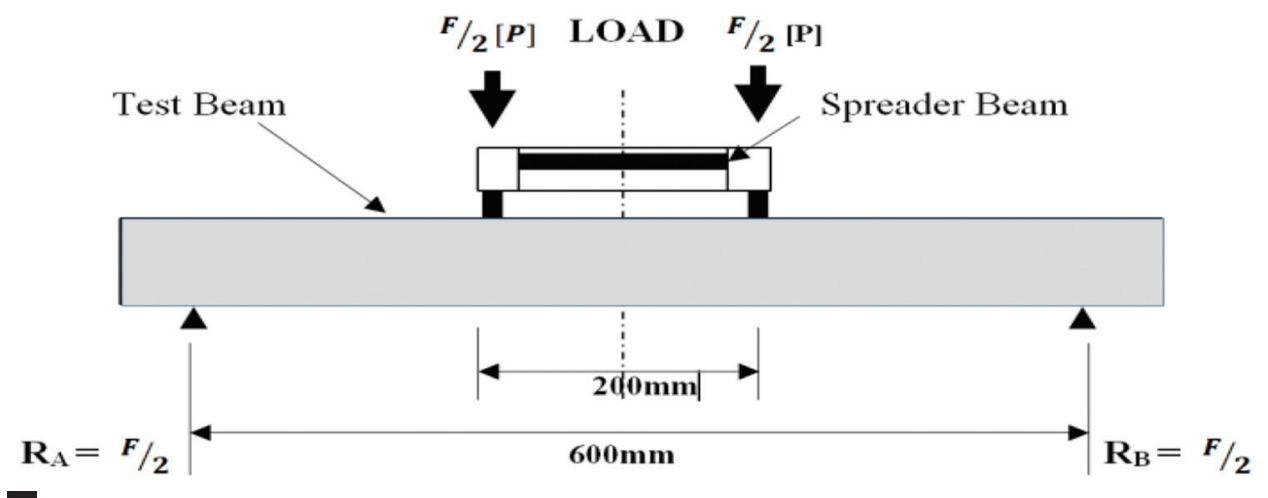

a

b

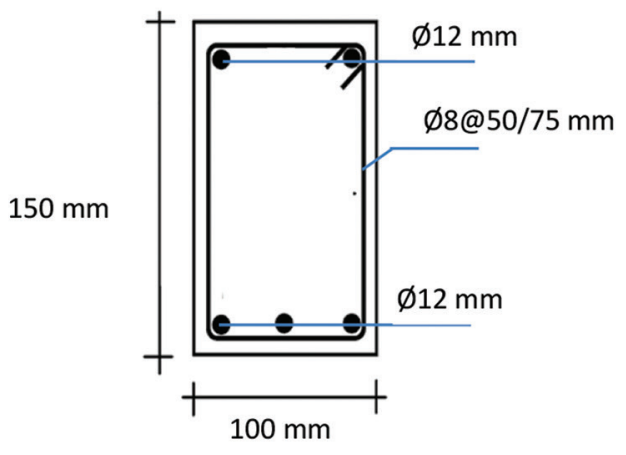

Fig. 3. (a) Loading set-up for the reinforced concrete beams, (b) typical cross-section with steel bars and stirrups.

finish and top surface. The completed beams and cubes were then left for settling down for approximately $24 \mathrm{~h}$ at room temperature. The following day they were de-molded and marked with the corresponding mix propositions. The beams and cubes were wrapped with plastic sheets then cured at room temperature (at about $20^{\circ} \mathrm{C}$ ). They were in the curing process for 28 days (Fig. 4). The cubes were not placed inside the curing tank to maintain consistency with the beams which were left for curing at room temperature.

\section{TeSt Results AND Discussions}

\section{A. Workability}

The results indicate that generally, partial or full replacement of FG with natural coarse aggregates has small effect on the initial slump values and the workability of the concrete. Fig. 5 shows the comparison of slump test results against various mixes studied; it can be seen that for 25 and $50 \%$ replacement of $\mathrm{FG}$ aggregates in terms of volume, the slump values have remained almost the same and a slight decrease for 75 and $100 \%$ resulting in a small change in the workability. For higher percentage replacement of FG aggregates, the reduction in workability could be attributed to the more angular grain shape texture than natural coarse aggregate which could have resulted in less fluidity and loss of workability as the percentage replacement of FG increased. Another factor could be an important absorption of water by the porous FG aggregates under dry conditions. 


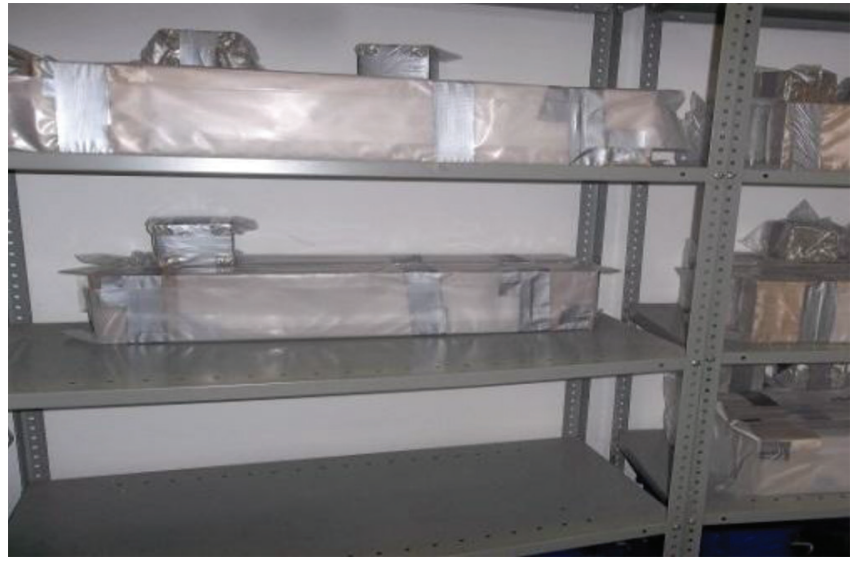

Fig. 4. Specimen wrapped with plastic sheets.

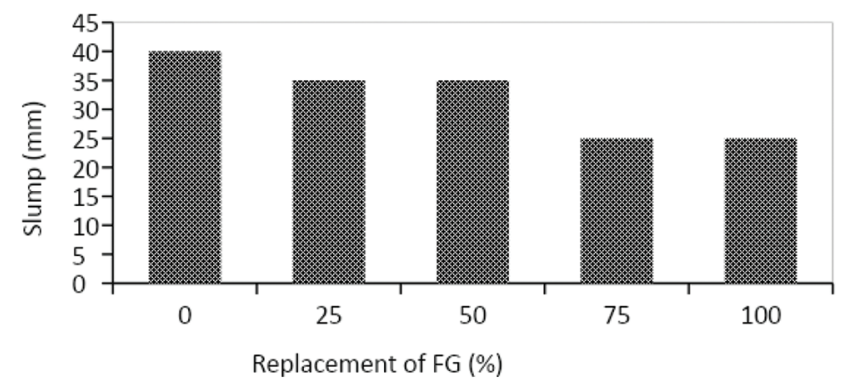

Fig. 5. Slump values.

\section{B. Flexural Behavior}

As described earlier, four-point loading flexural tests were conducted up to failure on all beams. The beams were tested as a simply supported beam under point loading test. The main focus of the present study was to observe the following characteristics for all the beams with the different percentage replacement of FG with NA, which are load-deflection behavior at mid-span for each load increment, load at which the first crack appears, mode of failure and crack pattern, and ductility behavior. Strain gauges are used to measure the deflection.

\section{Control Mix (0\% FG)}

The observations from all three beams in a mixture show almost the same trend; the first crack was recorded $55 \mathrm{~mm}$ away from the center line, between the two-point loads, inside the flexural zone at a load of $28 \mathrm{kN}$, which is approximately $42 \%$ of the ultimate failure load. Immediately after the first crack at $30 \mathrm{kN}$ load, a second crack $15 \mathrm{~mm}$ away from the centerline, which was also inside the flexural zone was observed. As the load increased, further hairline cracks started to appear. During the loading zone of $28 \mathrm{kN}-$ $48 \mathrm{kN}$, a total of six cracks appeared. These cracks started to form inside the flexural zone and with continuous load increments; they started to take a diagonal shape toward the compression zone of the beam without the width of the cracks changing significantly, suggesting that these were secondary flexural cracks, as secondary cracks appear under low loads and are widely spaced without influencing others to arise. They start to develop during the initial stages of cracking as a result of internal expansion and contraction of concrete constituents, in addition to the low flexural stresses due to the self-weight of the beam and the applied loads. When the load was gradually applied, the tensile stresses developing at the bottom fibers exceeded the flexural tensile stress of the concrete at $28 \mathrm{kN}$ which led to the development of these cracks. The main cracks started to form at a later stage than the secondary cracks. These were formed under the situation when a section was considered and there was a difference in strain between the steel and the concrete. Hassoun and Al-Manaseer (2008) stated that at low tensile stresses in steel bars, the number of cracks increases, whereas the widths of cracks remain small; as tensile stresses are increased, an equilibrium stage is reached. When stresses are further increased, the second stage of cracking develops, and crack widths increase without any significant increase in the number of cracks. Usually, one or two cracks start to widen more than the others, forming critical cracks. This was evident during the experiment. From $48 \mathrm{kN}$ up to failure load, only one additional crack was observed and a single crack started to widen and spread toward the point load indicating the development of the second stage of the cracking, that is, the main cracks.

The beams failed in the shape of a diagonal crack (known as shear failure) which started in the tension side of the beam and with progressive loads propagated toward the compression side under the point load failing at an ultimate load of $66 \mathrm{kN}$ with the mode of failure being a shear compression failure.

It was observed that the load-deflection curve is fairly linear before the first crack was formed at $28 \mathrm{kN}$ where the deflection was recorded to be $0.47 \mathrm{~mm}$, indicating that this was the elastic stage. After the occurrence of first crack, a slight change in the load-deflection behavior, as shown in Fig. 6, was observed, which was also linear up to the yield point where the deflection was recorded to be $1.38 \mathrm{~mm}$. With further load increase beyond the yielding of the reinforcement, the curve entered the plastic region and was almost horizontal up to the ultimate/failure load where the deflection was recorded to be $6.93 \mathrm{~mm}$.

\section{Mix $2(25 \%$ FG)}

The first hairline flexural crack in this beam occurred at the load of $28 \mathrm{kN}$ which is approximately $39 \%$ of its ultimate load. The position of this crack was roughly $135 \mathrm{~mm}$ away from the center line on the tension side of the beam. As the load increased to $36 \mathrm{kN}$, more secondary hairline flexural cracks were observed. At $56 \mathrm{kN}$ two additional cracks suddenly emerged approximately $200 \mathrm{~mm}$ away from the centerline of the beam. These were tension cracks as they initiated from the middle section of the beam. In total, there were nine cracks in this beam. The width of the tension cracks started to extend rapidly as the load increased. The failure load for this beam was $72 \mathrm{kN}$, approximately $8 \%$ higher load carrying capacity in comparison to the control beam with the same tension reinforcement. The failure was due to crushing of concrete and it was in the form of a diagonal crack which 
initiated from the middle of the beam suggesting that this was a shear compressive failure. The deflection when the first crack appeared at $28 \mathrm{kN}$ was measured $0.68 \mathrm{~mm}$ which is slightly higher than the control beam. Fig. 7 shows the loaddeflection behavior for this beam. Similar to the previous beams, the curve is linear during the un-cracked elastic stage, a slight change is then observed up to the yield point and a final turn leading to the ultimate strength. At the failure load of $72 \mathrm{kN}$, the deflection was $5.2 \mathrm{~mm}$ for this beam compared to $6.30 \mathrm{~mm}$ in the other suggesting that it is less ductile in comparison.

\section{E. Mix $3(50 \%$ FG)}

The first hairline flexural crack appeared approximately $150 \mathrm{~mm}$ away from the centerline at $22 \mathrm{kN}$. The incorporation of FG content seems to have reduced the load at which the first crack appeared in this specimen. This could be due to the fact that foam glass concrete has a less tensile strength in comparison to concrete from normal aggregates. As the load increased, further secondary cracks were observed which were all in the mid-span region between the point loads. In total, this specimen had six cracks. With 50\% replacement to normal aggregates by FG material, the load-carrying capacity has decreased by $23 \%$ and $27 \%$ in comparison to control $\operatorname{mix}(0 \% \mathrm{FG})$ and mix containing $25 \% \mathrm{FG}$, respectively. The mode of failure was a combination of shear and flexural failure. Initially, the crack formed near the bottom fibers of the beam and with the increase in load the crack started to expand and extend towards the top fibers, in particular, toward the point load, by the crack taking a diagonal shape. Compared to the previous beams, the load-deflection curve for this specimen as shown in Fig. 8 is unusual and does not show the three distinct stages expected in a typical reinforced concrete member. At the first crack, the deflection was $0.66 \mathrm{~mm}$ which is high compared to the previous beams and the curve is almost linear up to the yield point. The deflection at failure was $1.50 \mathrm{~mm}$ and before failure, this specimen did not provide ample warning of impending failure suggesting that it was less ductile to the previous beams.

\section{F. Mix $4(75 \%$ FG)}

Hairline flexural cracks started to appear at $20 \mathrm{kN}$ which is roughly $41 \%$ of its ultimate load. As the load increased; further, secondary cracks were observed. A total of seven cracks were found on this specimen. The position of the cracks was at various distances from the centerline and with

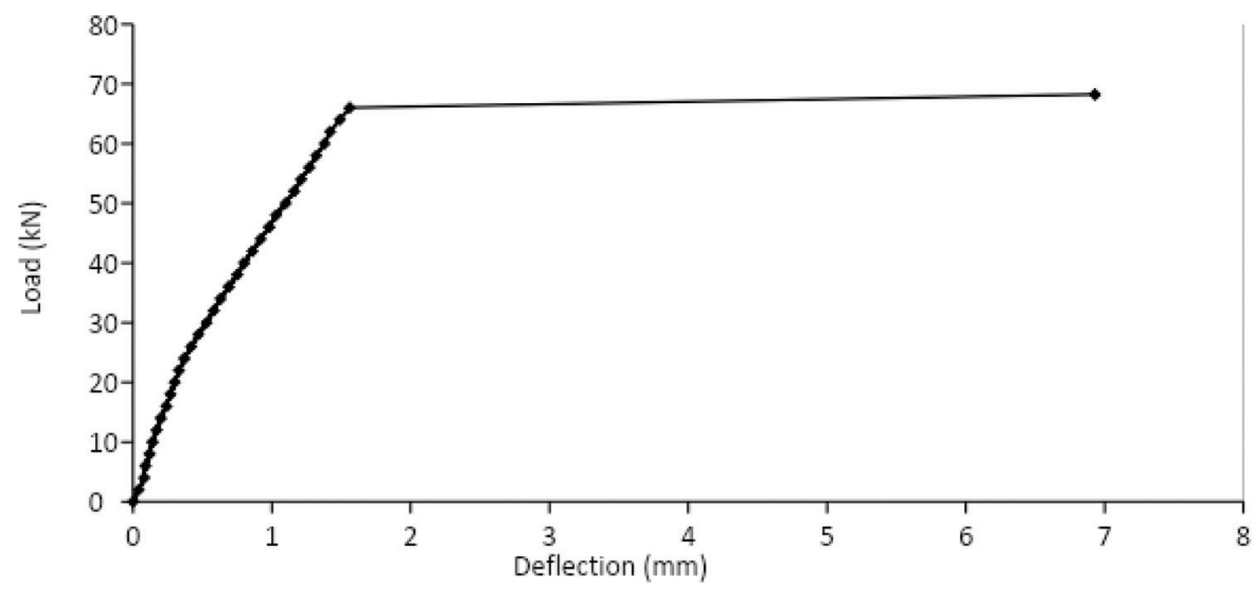

Fig. 6. Load-deflection behavior of the control mix ( $0 \% \mathrm{FG})$ beam.

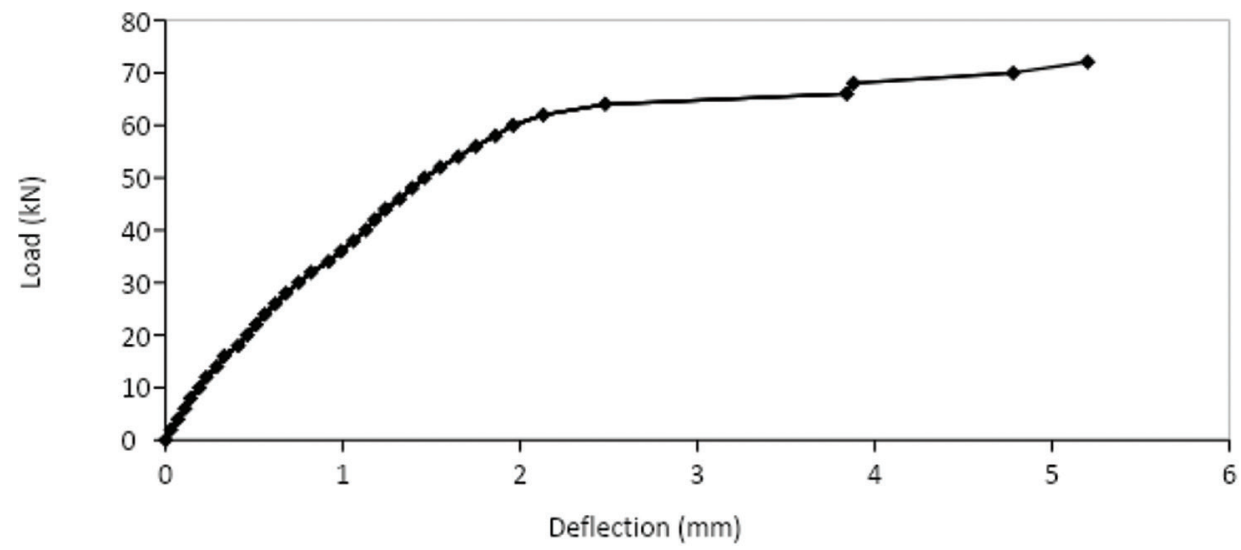

Fig. 7. Load-deflection behavior of $25 \% \mathrm{FG}$ beam. 
the exception of the third crack which appeared at $32 \mathrm{kN}$ toward the middle depth of the beam, whereas all other cracks originated from the bottom propagating toward the top. Failure load for this beam was $48.09 \mathrm{kN}$. The cracks which originated from the middle depth of the beam and extended at a faster rate compared to all other cracks. The failure also occurred due to this crack. The sudden emergence and rapid change in the width indicated that the failure mode for this beam was a shear failure. At first cracking, the deflection was recorded $0.38 \mathrm{~mm}$. As the load increased, it is shown in Fig. 9 that the deflection also increased, on failure the deflection was $2.75 \mathrm{~mm}$.

\section{G. Mix $5(100 \%$ FG)}

It was observed that the $100 \%$ replacement of $\mathrm{FG}$ dramatically reduced the load at which the first crack appeared. Hairline flexural cracks started to surface at $12 \mathrm{kN}$ which is almost $60 \%$ reduction to the load at which the first crack appeared with the $0 \%$ FG replacement. With further increase in the load additional cracks developed at the bottom surface of the beam relatively close to the support and rapidly started widening and propagating toward the point load. The failure occurred at $36 \mathrm{kN}$ by crushing with associated spalling of concrete cover in the compression zone. There were eight cracks in total for this beam. The beam failed in a mode of shear failure. The typical events of a load-deflection curve to failure were observed. It is shown in Fig. 10 that the curve is fairly linear up to $12 \mathrm{kN}$ identified as the first cracking of concrete. At yield point, the curve is still linear and the deflection was $0.83 \mathrm{~mm}$. However, between the yielding of tensile reinforcement and the ultimate strength, the curve did not behave in the usual manner, that is, horizontally; this is because the failure was brittle and provided little or no warning before failure. Fig. 11 shows the typical experimental load-deflection curves for all beams reinforced with 3T8 tension reinforcement, where the average values of the three tests for each mixture are shown.

\section{H. Load at First Crack and Ultimate Loads of Beams}

The appearances of reinforced concrete elements may greatly be reduced if cracks develop and more so when cracks are prominent. Excessive cracks and deep cracks affect the durability of concrete. Although strength may not be directly affected, the corrosion within the concrete can eventually cause the structures to fail. As beams deflect during loading, cracks occur first in the tension zone. Further loading tends to increase the width of the crack which gradually lead to

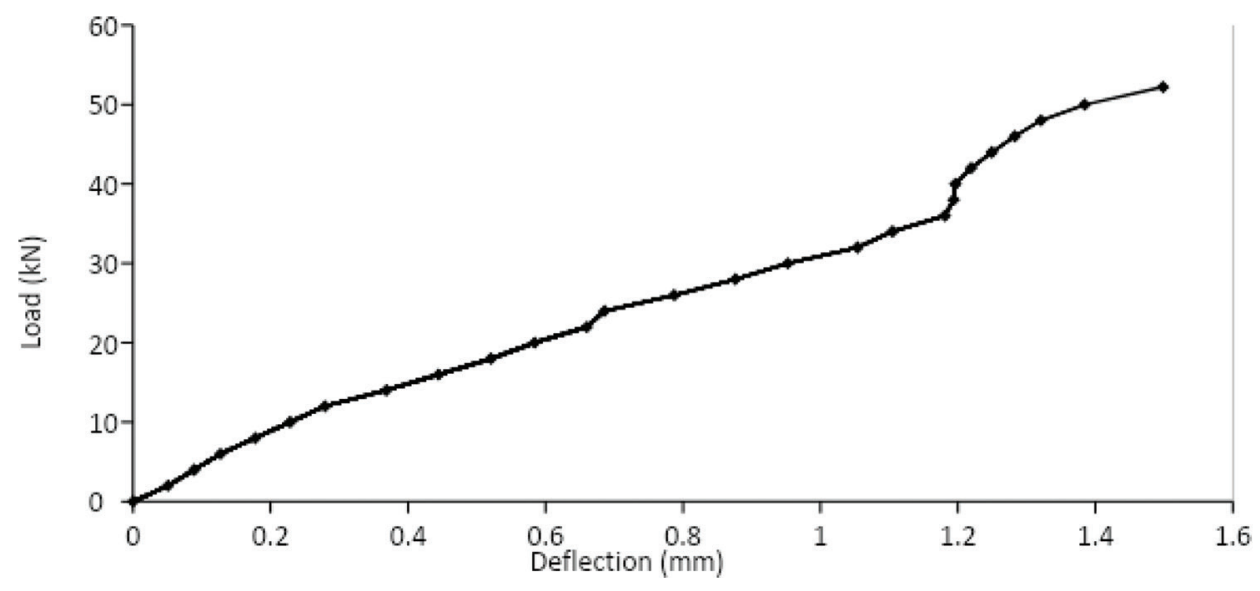

Fig. 8. Load-deflection behavior of 50\% FG beam.

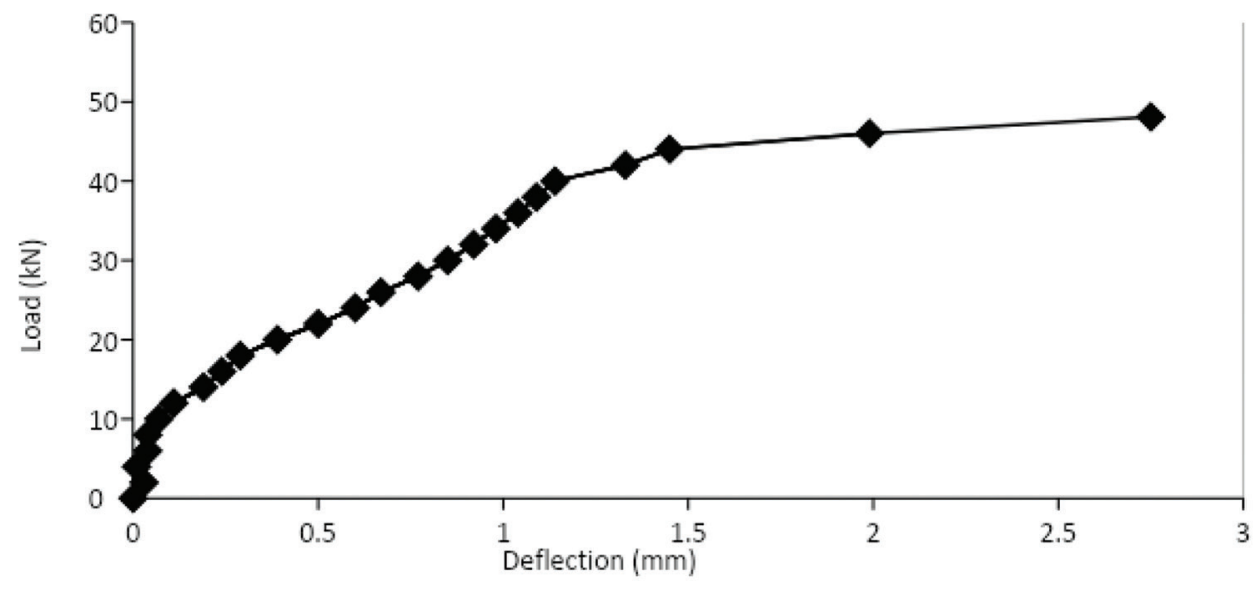

Fig. 9. Load-deflection behavior of $75 \%$ FG beam. 


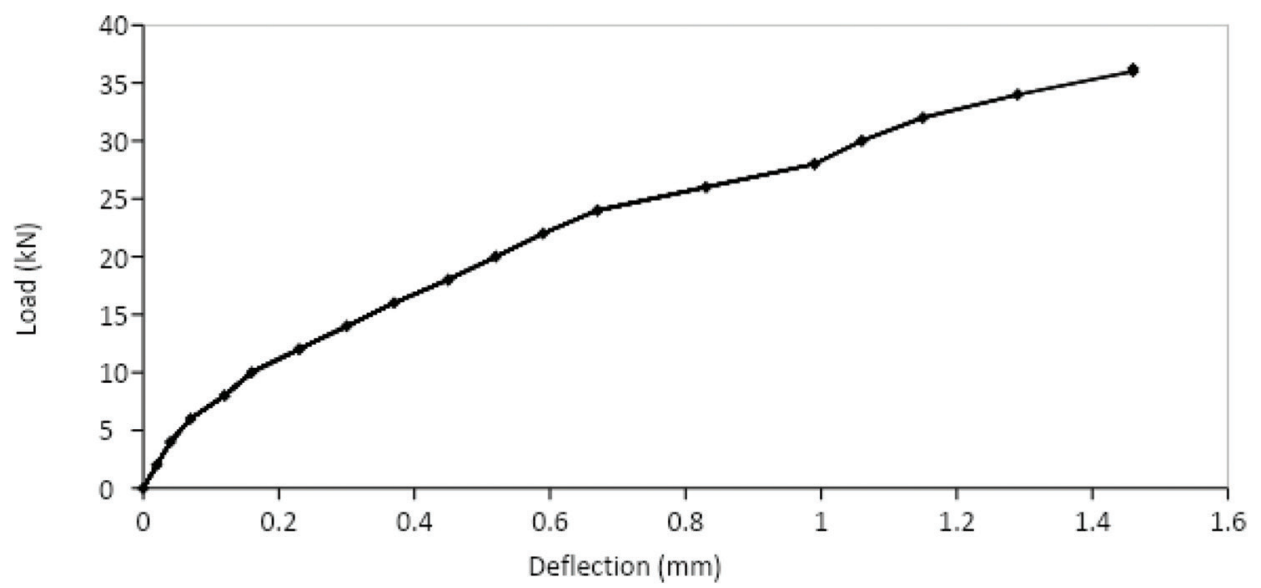

Fig. 10. Load-deflection behavior of $100 \%$ FG beam.

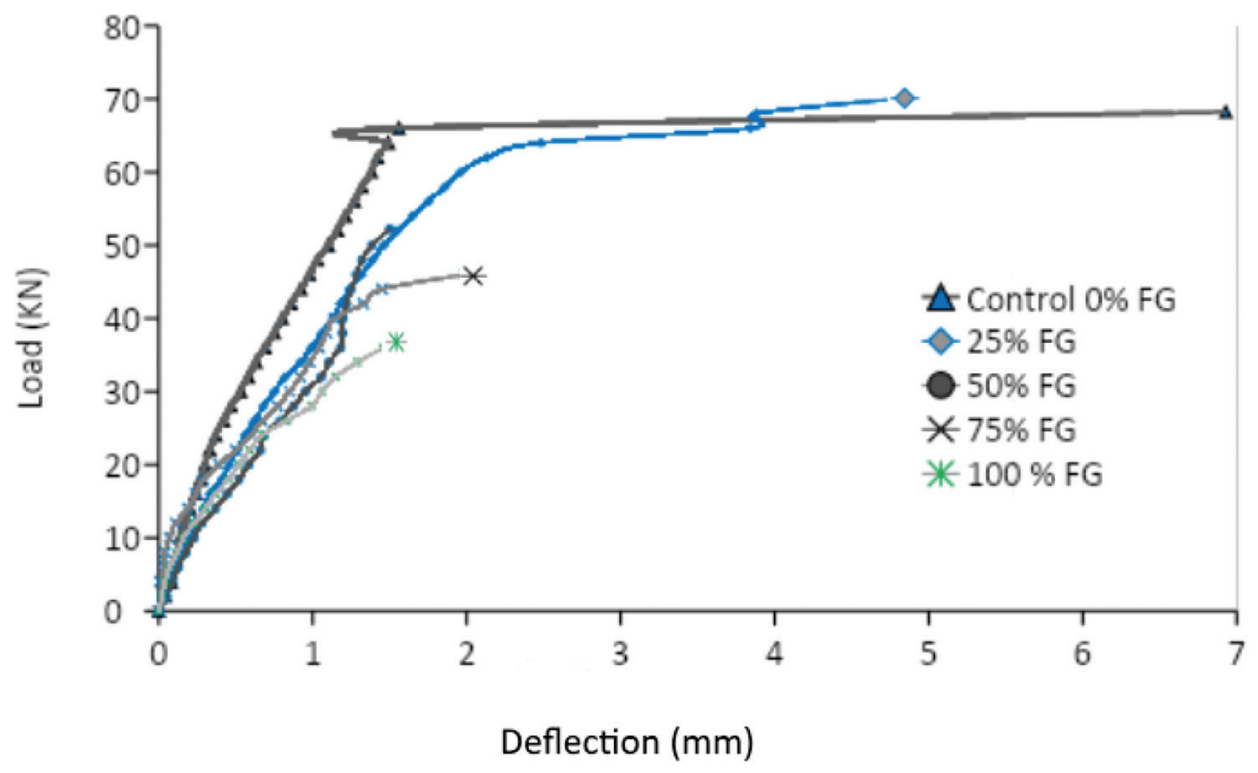

Fig. 11. Load-deflection curves for beams.

durability problems over time and may cause final failure (Adom-Asamoah and Afrifa, 2010).

During loading of beams, it was observed that the first crack in all the beams always started to form close to the mid-span of the beam. The cracks forming on the surface of the beam were mostly vertical cracks known as flexural cracks. For the beams, initial cracking occurred at about $38 \%-42 \%$ of its ultimate load. Lim, et al. (2006) reported that the parameter which provides distinct and conclusive evidence of slower growth of cracks is the amount of tension reinforcement, the higher amount is more effective at a given load level.

Fig. 12 shows the load at which the first crack appeared in the beams, it can be seen that as the percentage replacement of FG increases the first cracking load decreases, as in the first crack appears at a lower load. The reason for this could be due to reduction in the modulus of elasticity of FG concrete as Limbachya, et al. (2011) has reported that increasing the proportions of coarse FG aggregates in the concrete mix significantly reduces the modulus of elasticity of concrete and that up to $30 \%$ partial replacement to normal aggregates might be considered as the maximum amount that could be added without a major negative effect on the modulus of elasticity of FG concrete.

Fig. 13 shows the comparison of load-carrying capacity for all beams. It can be seen that as the percentage replacement of FG increases the load-carrying capacity decreases. For $100 \%$ foam glass replacement, there is a reduction of almost $50 \%$ in the load-carrying capacity in comparison to the control beam. It seems that the compressive strength of FG holds key significance in this reduction as the percentage reduction in concrete compressive strength correlates to the percentage of reduction in the load-carrying capacity. For example, the compressive strength of control mix was $30.67 \mathrm{MPa}$ and the load capacity of the beam from that mix was $68.23 \mathrm{kN}$ whereas for $100 \%$ replacement the compressive strength and failure load for the beam was $14.97 \mathrm{MPa}$ and $36.24 \mathrm{kN}$, respectively, indicating a reduction of almost $50 \%$ in strength and load-carrying capacity. 


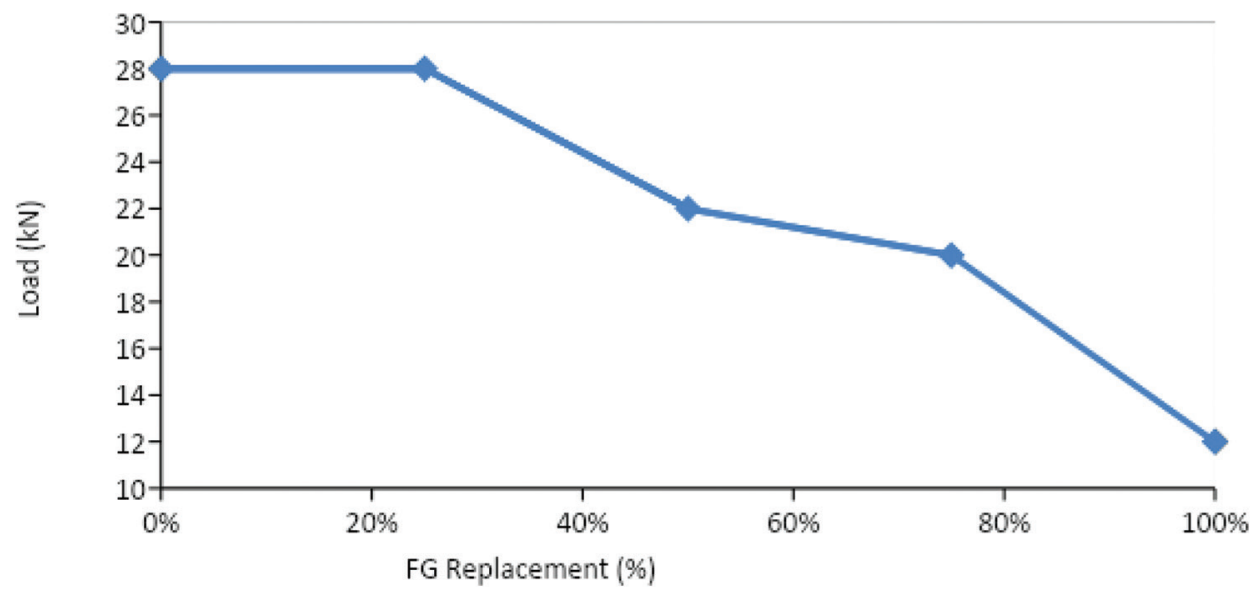

Fig. 12. Load at the first crack for all beams.

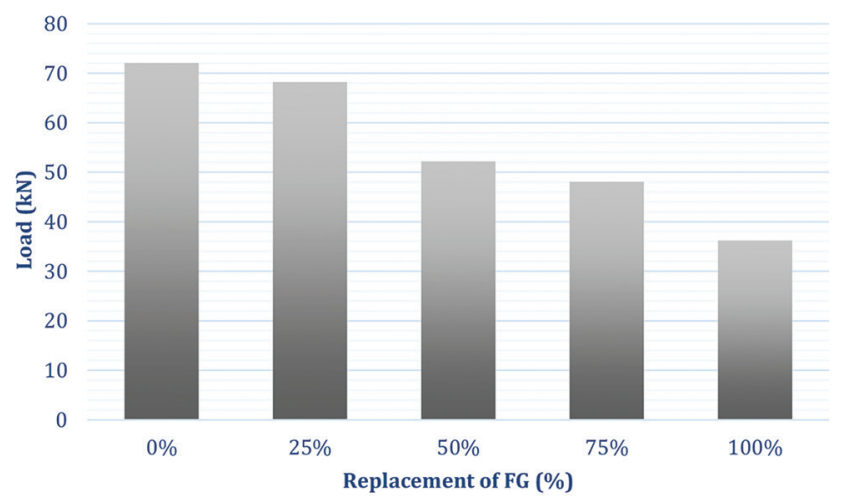

Fig. 13. Comparison of the load-carrying capacity of beams.

\section{Cracking Behavior and Mode of Failure}

Initially, vertical cracks known as flexural cracks started to form in the pure bending region. On further load increment, as shear stresses increased diagonal cracks were noticed which originated from the middle depth of the beam suggesting they were critical shear cracks and as load increased these cracks began widening at a faster rate and extending toward the point load, these cracks ultimately became the cause of failure, unlike the first secondary flexural cracks which appeared in the bending zone and remained almost the same until failure. The mode of failure in a structural reinforced concrete beam depends on a number of factors such as flexural tension reinforcement, flexural compression reinforcement, shear reinforcement, concrete compressive strength, and span to effective depth ratio. Although the beams in this study were designed to fail pure flexural mode, it can be concluded from analyzing Fig. 14 that failure for beams occurred mainly through combined diagonal tension and/or flexural-shear failure.

\section{J. Displacement Ductility}

Table II shows the ductility of the beams tested in the present study. In reinforced concrete structures ductility is significantly important as any member should be able to withstand large deflections at near maximum load-carrying

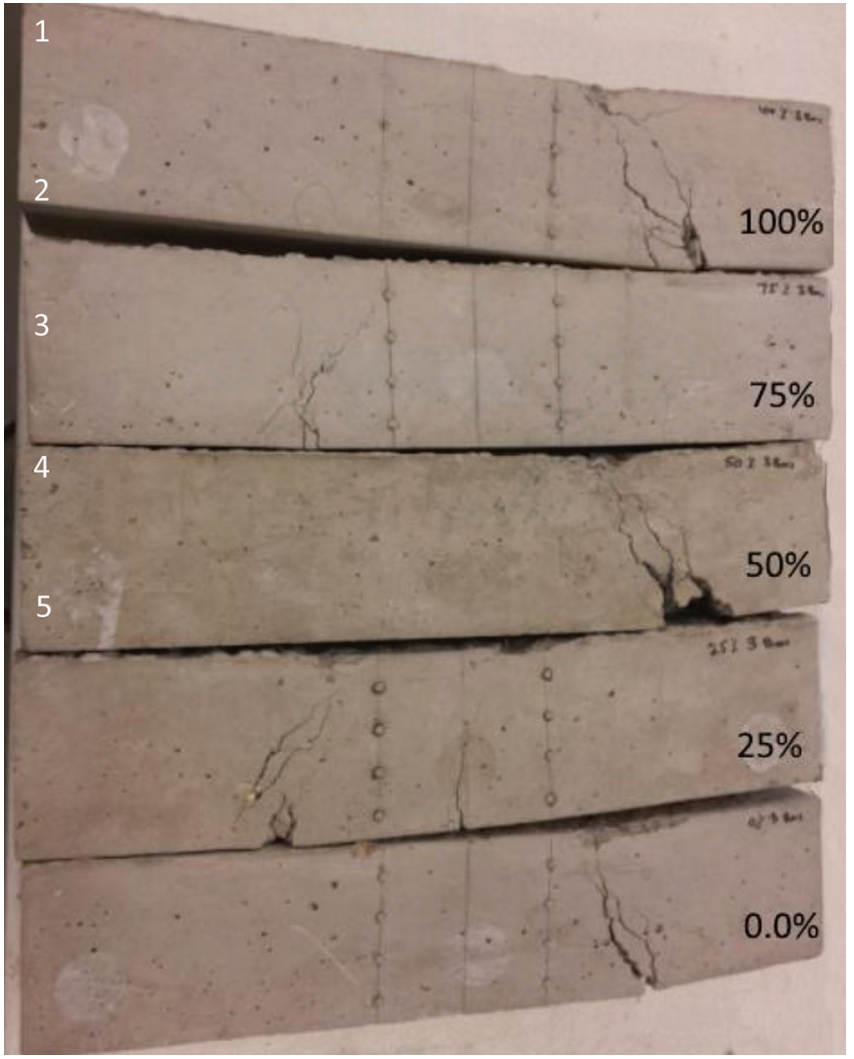

Fig. 14. Failure mode of the beams.

capacity, providing sufficient warning to the imminence of failure. Ductility allows stress redistribution and warning of impending failure. A structural member capable of withstanding large deformations before failure is a ductile material. In contrast; a material which fails at small strain without providing ample warning of impending failure is classified as brittle. Ashour (2000) has stated that members with a ductility ratio in the range of 3-5 have adequate ductility and can be considered for structural members subjected to large displacements such as sudden forces caused by earthquakes. The results presented in Table II show that displacement ductility ratio reduces by increasing FG. 


\section{K. Compressive Strength}

Fig. 15 shows the compressive strength complied with BS EN 12390-3:2009 for concrete containing different percentage replacements of FG aggregates. The experimental results suggest that the partial or full replacement of natural aggregate has, generally, resulted in a decrease to the compressive strength compared to the control mix. It can be seen that $75 \%$ or full replacement of NA by the FG aggregates has resulted in a considerable drop in the compressive strength of concrete which does not meet the minimum requirements of 28-day design strength

TABLE II

DisPlaCEMENT DUCTILITY RATIO OF ALL BEAMS

\begin{tabular}{|c|c|c|c|c|c|}
\hline \multirow[t]{2}{*}{ Beams } & \multicolumn{2}{|c|}{ Yield stage } & \multicolumn{2}{|c|}{ Ultimate stage } & \multirow{2}{*}{$\begin{array}{c}\text { Displacement } \\
\text { ductility ratio } \\
\mathrm{D}_{\mathrm{u}} / \mathrm{D}_{\mathrm{y}}\end{array}$} \\
\hline & Load $(\mathrm{kN})$ & $\begin{array}{l}\text { Deflection } \\
\mathrm{D}_{\mathrm{y}},(\mathrm{mm})\end{array}$ & Load $(\mathrm{kN})$ & $\begin{array}{c}\text { Deflection } \\
\mathrm{D}_{\mathrm{u}},(\mathrm{mm})\end{array}$ & \\
\hline $0 \% \mathrm{FG}$ & 62 & 1.42 & 68.23 & 6.93 & 4.88 \\
\hline $25 \% \mathrm{FG}$ & 54 & 1.65 & 72.07 & 5.2 & 3.15 \\
\hline $50 \% \mathrm{FG}$ & 36 & 1.2 & 52.21 & 1.5 & 1.25 \\
\hline $75 \% \mathrm{FG}$ & 40 & 1.14 & 48.09 & 2.75 & 2.41 \\
\hline $100 \% \mathrm{FG}$ & 28 & 0.99 & 36.24 & 1.46 & 1.47 \\
\hline
\end{tabular}

of $17 \mathrm{MPa}$ for lightweight aggregate concrete (Hedjazi, 2019), keeping in mind that the modulus of elasticity and the concrete strength is different in compression and tension (Atrushi, 2003). This is in agreement with the findings reported by Limbachya, et al. (2011).

The results also indicated that the higher the amount of the FG added, the larger the strength loss observed as shown in Fig. 16. For 25\% replacement, the strength loss was around $20 \%$ whereas for $100 \%$ replacement the reduction is above $50 \%$. It has been reported that the low density, high porosity, and high crushing value of FG particles have a significant contribution to the reduction of the compressive strength of FG concretes in comparison to concrete from normal aggregates (Limbachya, et al. 2010). Moreover, as previously stated the compressive strength has had a direct influence on the loadcarrying capacity of the beams, the higher the compressive strength is, the higher the load-carrying capacity was found.

\section{Density}

The densities of the cubes were measured on the same day as the structural tests were carried out complied with BS

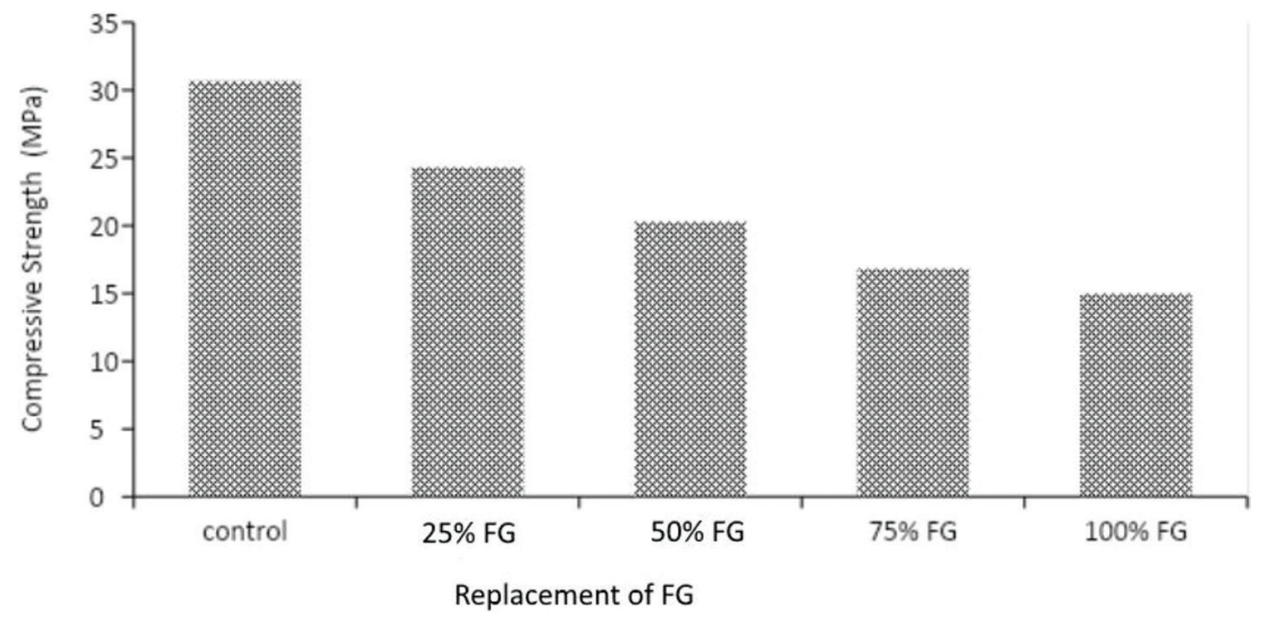

Fig. 15. Compressive strength of all mix proportions.

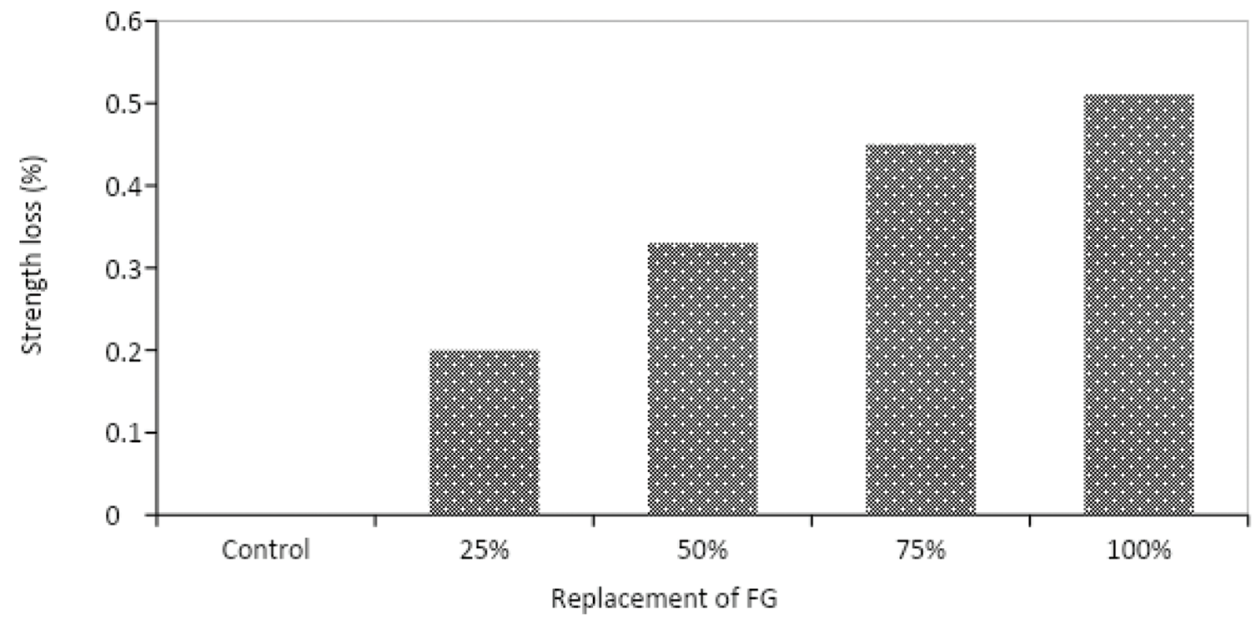

Fig. 16. Comparison of compressive strength loss. 


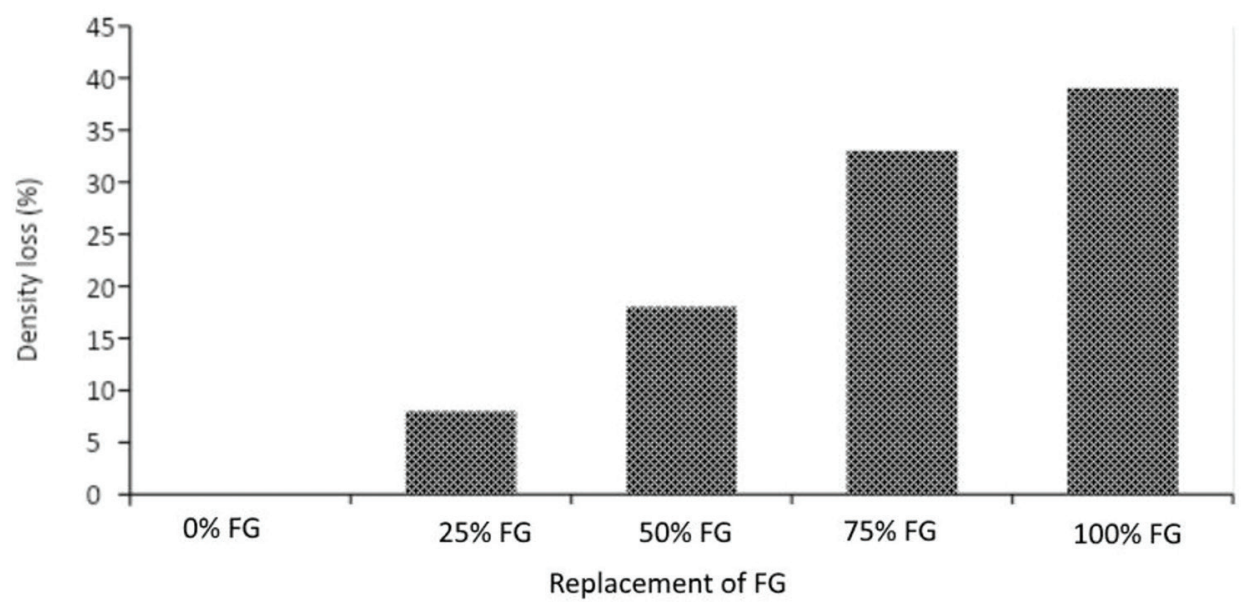

Fig. 17. Density reduction of all concrete cubes.

EN 12390-7:2009. Based on the results the density reduction graph as shown in Fig. 17 has been produced. It can be seen that incorporation of FG aggregates in concrete decreases the density. However, this reduction was predictable as FG is a lightweight material and its density is much lower than that of normal concrete.

It can be seen that by replacing $25 \%$ of normal aggregates with FG aggregates the decrease in density is about $8 \%$, which shows no significant reduction. However, for $100 \%$ replacement, the reduction is $39 \%$ which is quite significant. It was observed that the density has a direct influence on the concrete compressive strength as the reduction in compressive strength correlates to the reduction in density. This indicates that higher FG content in concrete will result in a lower density and compressive strength. This is in agreement with the findings reported by Limbachiya, Meddah and Fotiadou (2012).

\section{CONCLUSIONS}

According to the results obtained there is a great potential for the use of FG aggregates in concrete as a substitute to natural aggregates; because structural behavior of concrete containing FG is comparable to other types of lightweight aggregate concrete. Partial replacement of $25 \%$ FG aggregates showed no significant effects in all engineering properties studied such as flexural behavior, load-carrying capacity, first cracking load, ductility behavior, compressive strength, and density. According to the results obtained in the present study, the following conclusions can be drawn:

- Incorporation of FG aggregates showed little effect on the consistency of concrete but a decrease in the compressive strength and density of concrete. However, partial replacements of $25 \%$ and $50 \%$ have achieved the required 28-days strength.

- Reinforced concrete beams with FG had a higher deflection in comparison to beams prepared with normal aggregates. However, an increase in FG content slightly decreased the first cracking load but drastically reduced the load-carrying capacity.

\section{ACKNOWLEDGMENT}

I would like to thank Kingston University London for their hospitality, technical support, and valuable discussions during my Postdoctoral research work at the university. Thanks also to the University of Duhok for their support.

\section{REFERENCES}

Adom-Asamoah, M. and Afrifa, R.O., 2010. A study of concrete properties using phyllite as coarse aggregates. Materials and Design, 31(9), pp.4561-4566.

Ashour, S.A., 2000. Effect of compressive strength and tensile reinforcement ratio on flexural behaviour of high-strength concrete. Engineering Structures, 22(5), pp.413-423.

Atrushi, D.S., 2003. Tensile and Compressive Creep of Early Age Concrete: Testing and Modelling, Doctoral Thesis. Norwegian University of Science and Technology, Norway. Available from: https://www.ntnuopen.ntnu.no/ntnu-xmlui/ handle/11250/231168.

Babu, D.S.T., Babu, K. and Wee, T.H., 2005. Properties of lightweight expanded polystyrene aggregate concrete containing fly ash. Cement and Concrete Research, 35, pp.1218-1223.

British Standards Institution, BS EN 12350-2., 2009. Testing Fresh Concrete Part 2: Slump-test. British Standards Institution, United Kingdom.

British Standards Institution, BS EN 12390-2., 2012. Testing Hardened Concrete Part 2: Making and Curing Specimens for Strength Tests. British Standards Institution, United Kingdom.

British Standards Institution, BS EN 12390-3., 2009. Testing Hardened Concrete Part 3: Compressive Strength of Test Specimens. British Standards Institution, United Kingdom.

British Standards Institution, BS EN 12390-4., 2000. Testing Hardened Concrete Part 4: Compressive Strength, Specification for Testing Machines. British Standards Institution, United Kingdom.

British Standards Institution, BS EN 12390-7., 2009. Testing Hardened Concrete Part 7: Density of Hardened Concrete. British Standards Institution, United Kingdom.

British Standards Institution, BS EN 933-1., 1997. Tests for Geometrical Properties of Aggregates. Part 1: Determination of Particle Size Distribution Sieving Method. British Standards Institution, United Kingdom.

Demirboga, R. and Gu, R., 2003. The effects of expanded perlite aggregate, silica fume and fly ash on the thermal conductivity of lightweight concrete. Cement 
and Concrete Research, 33(5), pp.723-727.

Gennaro, R., Langella, A., Amore, M.D., Dondi, M., Colella, A., Cappelletti, P. and Gennaro, M., 2008. Use of zeolite-rich rocks and waste materials for the production of structural lightweight concrete. Applied Clay Science, 41(1-2), pp.61-72.

Hassoun, M.N. and Al-Manaseer, A., 2008. Structural Concrete: Theory and Design. John Wiley and Sons, Hoboken, New Jersey.

Hedjazi, S., 2019. Compressive Strength of Lightweight Concrete. IntechOpen, London.

Herki, B.M.A. and Khatib, J.M., 2016. Structural behaviour of reinforced concrete beams containing a novel lightweight aggregate. International Journal of Structural Engineering, 7(1), pp.1-30.

Hossain, K.M.A., 2004. Properties of volcanic pumice-based cement and lightweight concrete. Cement and Concrete Research, 34(2), pp.283-291.

Hurley, J.A., 2003. A UK Market Survey for Foam Glass. Glass: Research and Development, Final Report, the Waste and Resources Action Programme. WRAP Report, No. GLA-0015.

Kilic, A., Atis, C.D., Yasar, E. and Ozcan, F., 2003. High-strength lightweight concrete made with scoria aggregate containing mineral admixtures. Cement and Concrete Research, 33(10), pp.1595-1599.

Lim, H.S., Wee, T.H., Mansour, M.A. and Kong, K.H., 2006). Flexural behaviour of reinforced lightweight aggregate concrete beams. Journal of Advanced Concrete Technology, 4(3), pp.1-10.
Limbachiya, M., Meddah, M.S. and Fotiadou, S., 2011. Performance of granulated foamed glass concrete. Construction and Building Materials, 28(1), pp.759-768.

Limbachiya, M., Meddah, S. and Fotiadou, S., 2012. Performance of granulated foam glass concrete. Construction and Building Materials, 28(1), pp.759-768.

Rossignolo, J.A., Agnesini, M.V.C. and Morais, J.A., 2003. Properties of highperformance LWAC for precast structures with Brazilian lightweight aggregates. Cement and Concrete Composites, 25(1), pp.77-82.

Rostam, D., Ali, T. and Atrushi, S.D., 2016. Economical and structural feasibility of concrete cellular and solid blocks in Kurdistan region. The Scientific Journal of Koya University, 4(1), pp.1-7.

Shafigh, P., Hassanpour, M., Razavi, S.V. and Kobraei, M., 2011. An Investigation of the Flexural behaviour of reinforced lightweight concrete beams. International Journal of the Physical Sciences, 6(10), pp.2414-2421.

Shuab, H.A. and Ray, B., 1991. Flexural behaviour of high-strength lightweight concrete beams. ACI Structure, 88(1), pp.66-77.

Subasi, S., 2009. The effects of using fly ash on high strength lightweight concrete produced with expanded clay aggregate. Scientific Research and Essays, 4(4), pp. $275-288$.

Wuest, J., Denarié, E. and Bruhwiler, E., 2007. Measurement and Modelling of Fibre Distribution and Orientation in UHPFRC. In: Proceedings of the $5^{\text {th }}$ International RILEM. pp.259-266. 